\title{
De eerste leerstoel forensische pathologie
}

\author{
Citation for published version (APA):
}

Kubat, B. (2015). De eerste leerstoel forensische pathologie. Maastricht University. https://doi.org/10.26481/spe.20151211bk

Document status and date:

Published: 11/12/2015

DOI:

10.26481/spe.20151211bk

Document Version:

Publisher's PDF, also known as Version of record

\section{Please check the document version of this publication:}

- A submitted manuscript is the version of the article upon submission and before peer-review. There can be important differences between the submitted version and the official published version of record.

People interested in the research are advised to contact the author for the final version of the publication, or visit the DOI to the publisher's website.

- The final author version and the galley proof are versions of the publication after peer review.

- The final published version features the final layout of the paper including the volume, issue and page numbers.

Link to publication

\footnotetext{
General rights rights.

- You may freely distribute the URL identifying the publication in the public portal. please follow below link for the End User Agreement:

www.umlib.nl/taverne-license

Take down policy

If you believe that this document breaches copyright please contact us at:

repository@maastrichtuniversity.nl

providing details and we will investigate your claim.
}

Copyright and moral rights for the publications made accessible in the public portal are retained by the authors and/or other copyright owners and it is a condition of accessing publications that users recognise and abide by the legal requirements associated with these

- Users may download and print one copy of any publication from the public portal for the purpose of private study or research.

- You may not further distribute the material or use it for any profit-making activity or commercial gain

If the publication is distributed under the terms of Article $25 \mathrm{fa}$ of the Dutch Copyright Act, indicated by the "Taverne" license above, 
Prof. dr. Bela Kubat

Faculty of Health, Medicine and Life Sciences

\section{De eerste leerstoel forensische pathologie}


De eerste leerstoel forensische pathologie

Geachte rector mangnificus, geachte decaan en leden van het college van toezicht, dames en heren

Voor het eerst in de geschiedenis van Nederland heeft een universiteit, de Universiteit Maastricht, een leerstoel ingesteld voor het vak forensische pathologie. Deze leerstoel is een gezamenlijk project van het Nederlands Forensisch Instituut (NFI) en de Faculty of Health, Medicine and Life Sciencies. De positionering van deze leerstoel binnen de geneeskunde faculteit onderstreept het feit dat forensische pathologie een medische discipline is. Mijn opdracht voor deze leerstoel is het geven van onderwijs in dit vak en ik ervaar het als een bijzondere eer en een grote uitdagending deze leerstoel te mogen bekleden.

Ik zal kort ingaan op de inhoud van de klinische pathologie, binnen dat vak de obductie pathologie en dan de forensische pathologie. Ik zal kort de geschiedenis van de ontwikkeling van de forensische pathologie in Nederland schetsen. Daarna zal ik ingaan op de uitdagingen zoals ik ze zie. Ik hoop dus uit te kunnen leggen waarom het zo belangrijk is forensische pathologie in de medische opleidingen te verankeren en met welke problemen dit vak te kampen heeft.

Pathologie is de leer van de oorzaken en effecten van ziekte. In de klinische setting bepaalt de diagnose die de klinisch patholoog stelt mede de behandeling van de patiënt. De patholoog moet dus kennis hebben van oorzaken van ziekten 
om zijn onderzoek volledig in te zetten. Bijvoorbeeld zijn er, in het kader van kanker, specifieke erfelijke, genetische afwijkingen bekend die bepalend zijn voor verdere therapie en die de patholoog dient te onderzoeken. Mijn klinische collega's zijn dus vooral bezig met diagnostiek bij levende mensen.

Forensische pathologie is een bijzonder aandachtsgebied binnen het specialisme klinische pathologie en houdt zich bezig met onderzoek naar de doodsoorzaak in gevallen van evidente of vermeende dodingsdelicten. Ik zou dus kunnen zeggen dat moord en doodslag mijn dagelijks brood is. Dit zou echter tekort doen aan de forensische pathologie omdat ook in de forensische pathologie het herkennen van ziekten een rol speelt. Bijvoorbeeld in gevallen van onverwachts overlijden van met name jonge mensen kan er sprake zijn van een erfelijke aandoening. De forensisch patholoog dient hiermee rekening te houden, omdat de herkenning daarvan van belang kan zijn voor de nabestaanden.

Het woord forensisch stamt af van het Latijnse forensis, in een open plaats of publiekelijk, en werd rond 1650 ingevoerd voor de betekenis 'geschikt in de rechtbank'. Er wordt ook wel beweerd dat de eigenlijke oorsprong terug te voeren is op het onderzoek van de moord van Julius Caesar op 14 maart 44 voor Christus. Het onderzoek wordt beschreven door Svetonius in zijn werk 'Levens van 12 keizers' en waarvoor hij de Romeinse archieven heeft geraadpleegd. [1] Svetonius beschrijft het onderzoek van een arts, ene Antistius, die in het huis van Caesar een obductie op het lichaam van Caesar had verricht. Hierbij constateerde hij dat van de 23 toegebrachte letsels er slechts één dodelijk was, namelijk de 
tweede in de borst. De getuigenis van deze arts over zijn bevindingen werd publiekelijk ofwel forensis bekend gemaakt.

De bevindingen van Antistius zijn de oudste schriftelijk weergegeven rapportage van een gerechtelijke obductie in Europa. Deze beschrijving en de constatering dat slechts één van de 23 letsels dodelijk was en welke geven ook de twee meest belangrijke taken van forensische pathologie aan - het vaststellen van de doodsoorzaak en het bijdragen aan de reconstructie van de toedracht. Met andere woorden de beantwoording van de vragen WAAROM en HOE is iemand overleden. De onderzoekstechniek die hiervoor gebruikt wordt is het uitwendige en inwendige onderzoek van het lichaam, de autopsie, ook wel obductie of sectie genoemd.

Het woord autopsie komt van het Griekse autopsia, hetgeen 'zelf zien' betekent en is samengesteld uit de woorden autos - zelf, en opsis -oog. [2] De benaming obductie is mogelijk afgeleid van het Latijnse duco wat leiden of weg wijzen betekent. Het woord sectie is afgeleid van het latijnse snijden.

De Tsjechische arts, patholoog en filosoof Karel Rokitanský (1804-1879) en de Duitse bioloog, arts, antropoloog, en vader van de moderne (met name cellulaire) pathologie, Rudolph Ludwig Carl Virchow (1821-1902) zijn de grondleggers van de moderne obductie, zoals die tot op heden wordt uitgevoerd. Onze methode van obduceren is dus al meer dan 1 eeuw oud en wij medici danken veel van onze kennis aan dit medisch onderzoek. 
Obducties worden zowel in klinische als in forensische setting verricht. De aantallen klinische obducties dalen wereldwijd. [3,4] De redenen hiervoor zijn niet structureel onderzocht. Er zijn bevolkingsgroepen waar religieuze redenen een rol spelen, denk bijvoorbeeld aan de islam of het jodendom. Daarnaast vermoedt men dat artsen en nabestaanden vaak aannemen dat alles reeds bekend is uit de bij leven verrichte onderzoeken. Verder is het, in ieder geval in Nederland, zo dat een klinische obductie niet wordt vergoed, de ziekenhuizen betalen deze uit hun algemene budgeten.

De aantallen forensische obducties zijn in Nederland in de afgelopen 10 jaar gehalveerd. Ook hierin speelt mogelijk maatschappelijk ingegeven terughoudendheid ten aanzien van dit onderzoek een rol. Zonder te veel uit te wijden over het nut van de klinische obductie, wil ik toch enkele opmerkingen plaatsen. Vergelijkende studies tonen aan dat, ondanks nieuwe diagnostische technieken zoals de computertomografie en magnetic resonance immaging (CT en MRI scans) er substantiële verschillen van tot $50 \%$ bestaan tussen de bij leven gestelde diagnosen en de uitkomsten bij klinische obducties. $[3,5,6,7]$ Ook het argument dat deze nieuwe diagnostische technieken de obductie kunnen vervangen houdt, in ieder geval tot op heden, niet stand. Er zijn immers doodsoorzaken die de CT en MRI scans (nog) niet aan kunnen tonen. [7] Daarbij dient men zich te realiseren dat in de klinische setting de obductie het laatste kwaliteitscontrole middel is. Dit geeft aan dat de obductie nog steeds een belangrijke rol speelt in de monitoring van de kwaliteit van de behandeling en dus van een ziekenhuis. Het belang van het verrichten van klinische obducties zou daarom ook door de ziektekostenverzekeraars 
erkend moeten worden, bijvoorbeeld door er een vergoeding tegenover te stellen.

Voor wat betreft forensische obducties is er nog recentelijk daarvoor gepleit meer forensische obducties in Nederland te verrichten omdat men vermoedt dat in de huidige situatie veel dodingsdelicten niet opgemerkt worden.

Obducties hebben daarnaast in academische opleidingsinstellingen een tweede belangrijke functie. Uit onderzoek is gebleken dat studenten geneeskunde, aanstaande artsen dus, door het bijwonen van klinische obducties leren verschillende klachten en bevindingen beter te combineren en zo de mechanismen van ziekten, de pathofysiologie, beter te begrijpen. [8] Een beter begrip van deze processen zal ze in de toekomst in staat stellen oorzaken van ziekten eerder op te sporen. Van hetzelfde leerproces profiteren ook artsen in opleiding tot een specialist, bijvoorbeeld tot patholoog of internist.

Een obductie is dus een belangrijke medische handeling, net als de longfoto of blindedarm operatie. Dit weerspiegelt ook de wetgeving door de obductie onder dezelfde wetten te plaatsen als diagnostische onderzoeken van de levenden. Deze onderzoeken, ook de obductie, vallen onder dezelfde wettelijke bepalingen.

Voor een klinische obductie is instemming van de patiënt of een familielid nodig. Dit is anders bij de forensische obductie.

Forensische ofwel gerechtelijke obductie wordt gelast door de officier van justitie. In dat geval hebben de nabestaanden geen inspraak in het wel of niet plaats vinden van de obductie. Een forensische obductie wordt in principe niet 
anders verricht dan de klinische obductie. Zij begint met de uitwendige schouwing van lichaamskenmerken en uitwendige letsels. Dan volgt de inwendige schouwing waarbij de letsels en ziekelijke afwijkingen aan de inwendige organen worden geïnventariseerd. Vaak worden ook aanvullende onderzoeken, zoals microscopisch weefselonderzoek naar ziekelijke afwijkingen en toxicologisch onderzoek naar vergiftigingen, verricht. De rapportage wordt verstrekt aan de officier van justitie, die deze, in geval van strafvervolging, in het strafdossier verstrekt aan de rechters en betrokken advocaten. Andere partijen, zoals de nabestaanden of behandelende artsen, kunnen een verzoek richten aan de officier van justitie de obductie rapportage te krijgen en de praktijk leert dat, waar vanuit juridisch standpunt mogelijk, de officieren van justitie deze verzoeken ook honoreren.

In Nederland zijn in totaal vijf forensisch pathologen, waarvan vier werkzaam in het NFI in Den Haag, ik ben er één van. De forensisch pathologen verrichten onderzoek van overledenen. Onderzoek van levende slachtoffers wordt in Nederland niet door de forensisch pathologen verricht maar door forensisch geneeskundigen. Hierin verschilt het systeem met vele omringende landen waar de forensisch medisch specialist zowel overleden als levende slachtoffers onderzoekt. De Nederlandse forensisch pathologen zijn opgenomen in het Nederlands Register voor Gerechtelijk Deskundigen (NRGD). Dit is een onafhankelijke instantie die, middels toetsing aan de hand van internationaal erkende eisen, een lijst van 'geaccrediteerde' deskundigen opstelt. Registers voor andere medisch forensische vakken, zoals bijvoorbeeld forensische geneeskunde, zullen volgen. 
Het NFI is een onafhankelijk forensisch instituut met vele disciplines, waaronder de forensische pathologie, en het resideert onder het Ministerie van Veiligheid en Justitie. Het is dus tot voor kort niet verbonden geweest aan een academische instelling. In de afgelopen jaren zijn verschillende activiteiten ontwikkeld door het NFI met als doel nauwere contacten met academische instellingen te ontwikkelen, ten behoeve van samenwerking op het gebied van onderwijs en onderzoek. De leerstoel forensische pathologie is één van de resultaten van deze inspanningen.

De geschiedenis van de forensische pathologie in Nederland begint na de Tweede Wereldoorlog. Voor die tijd werden artsen met interesse voor forensische problematiek ad hoc benoemd. Universitaire instellingen en ziekenhuizen hadden geen belangstelling voor forensisch medisch onderzoek en weigerden vaak zelfs dergelijke onderzoeken te faciliteren.

In het kader van de reorganisatie van het justitieel systeem in 1945, gebaseerd op het Ministerieel Besluit van 30 juli 1045, werd het Gerechtelijk Laboratorium opgericht als een onafhankelijk forensisch instituut onder het Ministerie van Justitie. Oorspronkelijk was het de bedoeling in het Gerechtelijk Laboratorium een medisch forensisch instituut te integreren. Uiteindelijk, echter, werd in 1951 voor een separaat instituut gekozen, het Gerechtelijk Geneeskundig Laboratorium, dat wegens (wederom) weinig interesse vanuit academische instellingen eveneens onder de Ministerie van Justitie geplaatst werd. De eerste directeur van het Gerechtelijk Geneeskundig Laboratorium was de patholoog dr. Zeldenrust, die zijn collega's rekruteerde onder de klinisch pathologen. 
Sedertdien kun je in Nederland forensisch patholoog worden alleen indien je de medische specialisatie klinische pathologie hebt. In 1999 werden het Gerechtelijk Laboratorium en het Gerechtelijk Geneeskundig Laboratorium samengevoegd tot het Nederlands Forensisch Instituut, het NFI. De aantallen van de in forensische pathologie geïnteresseerde klinisch pathologen waren nooit groot. In de tachtiger jaren verrichten drie, later vier pathologen circa 600 forensische obducties per jaar. Tegenwoordig verrichten wij met z'n vieren circa 300 obducties per jaar. Dit zou de indruk kunnen wekken dat de werkbelasting gehalveerd is, dit is echter niet zo. Door de komst van nieuwe onderzoekstechnieken op medisch en forensisch-technisch gebied zijn de eisen aan, en daarmee de bewerkelijkheid van ons onderzoek toegenomen. Internationaal geniet het NFI hoog aanzien, hetgeen af te lezen is uit het feit dat het werk verricht voor het Internationaal Strafhof en ad hoc tribunalen zoals het Joegoslavië Tribunaal en regelmatig gevraagd wordt voor onderzoeken door buitenlandse openbare ministeries, bijvoorbeeld van Nieuw Zeeland of Australië.

Recentelijk is, met de komst van geavanceerde beeldvormende technieken, met name de computertomografie ofwel de CT scan, een nieuwe onderzoeksmethode toegevoegd aan de obductie. Voorafgaande aan de obductie kan het lichaam worden gescand, er wordt een postmortale total body CT scan gemaakt. Deze scan is om te beginnen een perfecte inventarisatie van de toestand voor de obductie. Het legt afwijkingen vast die mogelijk tijdens de obductie niet of minder goed te beoordelen zijn, denk bijvoorbeeld aan botbreuken. Ook is het gebleken dat de reconstructie van schotkanalen vaak exacter op de CT scan mogelijk is dan tijdens de obductie. Anderzijds is het tot op heden veelal niet 
mogelijk verschillende afwijkingen, zoals onderhuidse bloeduitstortingen ofwel blauwe plekken, steekletsels en vele ziekelijke orgaanafwijkingen, op de CT scan te zien. [9] Het is te verwachten dat verdere technische ontwikkeling en betere toegankelijkheid van de MRI (magnetic resonance immaging) voor postmortaal onderzoek (onderzoek na de dood) in de toekomst ook een toegevoegde waarde zullen hebben. [10] De rol van postmortale radiologie zal dus in de nabije toekomst groeien. Wetenschappelijk onderzoek - research, en validering van deze technieken zullen hierin een cruciale rol spelen. In de omringende landen wordt postmortale radiologie al vaak, soms zelfs standaard uitgevoerd en er vindt ook veel research plaats.

Wil men het huidige niveau van forensisch medisch onderzoek in Nederland handhaven zal de overheid geld ter beschikking moeten stellen voor de ontwikkeling, validering en implementatie van opkomende medische onderzoeksmethoden, waaronder postmortale radiologie.

Dat mijn visie ten aanzien van postmortale radiologie door anderen gedeeld wordt blijkt uit het gegeven dat de Faculty of Health, Medicine and Life Sciencies van Universiteit Maastricht de ontwikkeling van forensische en postmortale radiologie ondersteunt, ondermeer door het instellen van een leerstoel 'Forensische en postmortale radiologie'. Samen met de reeds bestaande leerstoel 'Forensische Radiologie in het bijzonder de Forensische Kinderradiologie' in Amsterdam opent dit nieuwe mogelijkheden voor ontwikkeling en de daaruit voortvloeiende verbetering - ik ben hier heel blij mee want nu heb ik 'companions in crime'. 
De opdracht van mijn leerstoel is echter niet gericht op research maar op onderwijs van forensische pathologie. Onderwijs van een vak is zeer belangrijk, niet alleen verhoogt onderwijs het algemeen niveau, maar het maakt mensen, in dit geval artsen of aanstaande artsen, bekend met het vak. Hier geld dan ook 'onbekend is onbemind'. Tot zo'n tien jaar geleden werd in Nederland nauwelijks onderwijs in forensisch medische vakken gegeven aan geneeskunde studenten en artsen en tot op heden is dit onderwijs geen structureel onderdeel van geneeskunde curricula. Tekort aan kennis bij medisch personeel kan een aantal negatieve effecten hebben.

Ten eerste is er de kans dat door onvoldoende kennis er onvoldoende aandacht besteed wordt aan signalen van misdrijven, denkt u bijvoorbeeld aan mishandeling. Enerzijds kan dan niet tijdig worden ingegrepen, anderzijds is een valselijke verdenking dramatisch voor zowel de verdachte als voor degene de verdenking uitspreekt. Vroege en correcte herkenning in de klinische setting is dus zeer belangrijk. Bij het woord mishandeling wordt al snel gedacht aan kinderen, maar met de opkomst van de 'participatie maatschappij', die onze politiek recentelijk heeft ingesteld, is het te verwachten dat er ook een toename zal zijn van tekort aan, ik noem het maar, 'participanten' of onmacht bij de mantelzorgers, hetgeen kan resulteren in een toename van verwaarlozing of mishandeling van ouderen, een groep die nog maar net in het forensische blikveld komt.

Ten tweede is een onbekend vak niet gauw een carrière keuze van aankomend talent. Dit bleek toen nog enkele jaren geleden er geen kandidaten te vinden 
waren voor vacatures forensische pathologie in het NFI. Hierbij speelde ook de ontkoppeling van dit vak van academische instellingen een rol.

In de omringende Europese landen is forensische geneeskunde en pathologie een onderdeel van een eigen medisch specialisme en de instituten zijn meestal ingebed is in academische instellingen, universiteiten. Dit heeft het voordeel dat de specialisten een vaste bijdrage leveren aan geneeskunde curricula en zich bovendien kunnen bedienen van ondersteuning van deze instellingen voor wat betreft de diagnostische middelen en research. Deze universitaire inbedding biedt bovendien de mogelijkheid een academische carrière te realiseren.

In Nederland was het aanvaarden van de positie van forensisch patholoog bij het NFI tot voor kort het eindpunt van de carrière mogelijkheden binnen dit vak.

Uit onderzoek naar factoren die bepalend zijn voor de keuze van specialisatie onder Zwitserse studenten geneeskunde blijkt dat juist carrière perspectief, naast levensdoelen, een belangrijke bepalende factor is voor hun keuze van specialisatie na de geneeskunde studie. [11] Indien perspectieven ontbreken zullen juist de geëngageerde en vakinhoudelijk goed onderlegde mensen forensische pathologie niet overwegen. Ook met he oog op dit aspect is academische inbedding van forensische pathologie van groot belang.

Wat de Nederlandse overheidsinstanties betreft geven deze geen blijk van het besef dat forensische pathologie bestaat en de aandacht voor forensisch medische problematiek is nog maar net opgekomen. Zo spreekt bijvoorbeeld de Gezondheidsraad in zijn Werkprogramma 2013 in paragraaf 7.2 over versterking 
van de forensische geneeskunde zonder ook de forensische pathologie te vernoemen. Wel erkent de Gezondheidsraad het probleem van de beperkte academische vorming op het forensisch medisch gebied en stelt hierover het volgende:

'Nieuwe wetenschappelijke kennis dringt daarom onvoldoende door in de beroepspraktijk. Verder zijn er lacunes in het basiscurriculum van artsen, terwijl enige forensisch-medische kennis daar wel degelijk van belang is; denk aan het herkennen van mishandeling en niet-natuurlijke doodsoorzaken'. Verder stelt dit stuk dat het is ... 'Tijd voor een advies over de kennisinfrastructuur die voor de forensische geneeskunde nodig is.' [12] Dit advies is inderdaad ingewonnen door de staatssecretaris van Onderwijs, Cultuur en Wetenschap (OCW). Er werd een commissie ingesteld die een document opgesteld heeft genaamd Forensische geneeskunde ontleed; naar een volwaardige plaats voor een bijzondere discipline dat op 26 april 2013 aan de staatssecretaris werd aangeboden. [13]. Terwijl het stuk gedegen antwoord geeft aan de gestelde vragen gaat ook dit advies voorbij aan de rol van forensische pathologie binnen het forensisch medisch onderzoek. Toch zijn de conclusies ten aanzien van academische inbedding, research mogelijkheden en de aantrekkingskracht van het vak voor aankomende artsen één op één overdraagbaar op forensische pathologie. Zodoende kan de term 'forensische geneeskunde' in dit rapport evengoed worden vervangen door 'forensisch medische vakken'. Zo stelt de commissie dat forensische geneeskunde, ik vervang door forensisch medische vakken, herkenbaar onderdeel dienen te worden in het bestaande basiscurriculum geneeskunde en moet deze expertise binnen bestaande specialisaties worden uitgebreid. Tevens benadrukt het 
rapport het belang van bevordering van onderzoek op dit gebied. Problemen met de incorporatie van forensisch medisch onderwijs in academische curricula zijn niet nieuw en niet beperkt tot Nederland. Reeds in 1979 brachten Sexton et al dit probleem in de USA onder de aandacht. [14] Het verrichten van medisch forensisch onderzoek stuit in de praktijk op het probleem dat medische fondsen naar forensische fondsen verwijzen en forensische fondsen, die met name op technisch onderzoek focussen, naar medische fondsen verwijzen. Ook dit probleem is niet exclusief Nederlands gezien het onderzoek van Nolte in de USA. [15] Hier dient opgemerkt te worden dat research de basis is van behoud van 'up to date' kwaliteit in de praktijk.

Navraag bij de leden van de kommissie leert dat er tot op heden, anno 2015, slechts mondjesmaat een begin is gemaakt met de invoering van een aantal van de in het rapport aan de staatsecretaris geformuleerde verbeteringen. In het Werkprogramma 2014 van de Gezondheidsraad wordt op het forensisch medisch onderwerp niet meer ingegaan. [16]

Één van de conclusies die me hieruit kan trekken is dat ondanks intensieve pogingen van de vakmensen tot op heden de doelen niet zijn gerealiseerd. Hulp van de overheid zowel voor de invoering van medisch forensische vakken in medische curricula als voor de financiering van research zou daarom zeer welkom zijn.

Zoals ik al gezegd heb is het doel van deze leerstoel onderwijs geven op mijn vakgebied. Ik heb mij tot doel gesteld onderwijs te ontwikkelen voor studenten geneeskunde, assistenten in opleiding tot patholoog en assistenten in opleiding tot andere, klinische specialismen. Ook al is onderwijs in forensisch medische 
vakken nog niet in Maastricht in het basiscurriculum opgenomen, is het toch gelukt $100 \%$ van de studenten te bereiken door onderwijs te geven aan coassistenten chirurgie. Dit onderwijs is in november gestart.

Door de inbedding van mijn functie binnen de afdeling klinische pathologie heb ik de mogelijkheid enerzijds theoretisch onderwijs aan de aanstaande pathologen te geven, anderzijds kan ik praktische vaardigheden leren aan de hand van klinische obducties. In de toekomst zou ik graag in samenwerking met de afdeling klinische pathologie een verdiepingsstage klinische obductiepathologie en forensische pathologie ontwikkelen een deze ook aan aanstaande pathologen van ander opleidingscentra aan te bieden. Een voorwaarde hiervoor is het verrichten van forensische obducties in Maastricht. Ook dit staat op mijn lijstje. Dit moet echter volgens de strikte kwaliteitsnormen van het NFI worden uitgevoerd, en dat behoeft gedegen voorbereiding en goede organisatie. Indien het lukt zal het vruchten afwerpen niet alleen binnen het onderwijs van aanstaande pathologen maar ook bijdragen aan de ontwikkeling van postmortale radiologie. Structureel onderwijs van forensisch medische vakken aan arts assistenten van andere klinische disciplines moet nog worden ontwikkeld, maar vindt al incidenteel plaats.

Heb ik nog andere plannen? Ja, die heb ik. Ik geloof dat postmortale radiologie toegevoegd zou moeten worden aan de lijkschouw. Hierdoor zou het mogelijk zijn in een aantal gevallen de doodsoorzaak exacter vast te stellen, denkt u bijvoorbeeld aan hersenbloedingen of inwendige bloedingen door een gebarsten bloedvat. Indien dit ook nog gecombineerd zou worden met een screening naar vergiftigingen zou het bijdragen aan de herkenning van verdachte sterfgevallen 
en exactere landelijke statistiek van doodsoorzaken opleveren. Het zou dus zowel juridisch als maatschappelijk van belang zijn.

Daarnaast zou ik, gezien de kwalitatief hoge kennis op het forensisch medisch gebied in Nederland, een aantal internationale cursussen willen ontwikkelen en aanbieden. Zodoende zou Nederland een opleidingscentrum kunnen worden voor forensisch medische vakken in Europa. Door dit onderwijs zou een bijdrage worden geleverd aan de harmonisatie van forensisch medisch onderwijs zoals dit nagestreefd wordt door de European Council of Legal Medicine. [17]

Dames en heren, mijn prachtig vak, de forensische pathologie, wordt in Nederland met grote toewijding en passie beoefend door het handjevol collega's. Gezien de problemen die wij ervaren doet het goed aan deze vooruitstrevende universiteit deze leerstoel te bekleden en zo een bijdrage te kunnen leveren aan verdere ontwikkeling van de forensisch medische wetenschappen. Hiervoor wil ik graag mijn grote dank uitspreken aan allen die mij gesteund hebben en steunen binnen de Universiteit Maastricht en het NFI.

Dr. Ellen van Berkel was mijn vaste steun en begeleider, eerst op de bedevaart van faculteit naar faculteit met de vraag naar een leerstoel forensische pathologie, later bij de gesprekken in Maastricht. Haar steun was cruciaal. Ellen, dank je voor je vertrouwen en hulp.

Professor Scherpbier was mijn contact gedurende zowel de informatieve fase als tijdens de verdere besprekingen. Hij gaf mij het gevoel welkom en veilig te zijn op dit onbekend terrein, hiervoor mijn dank. 
Dr. Wim Heinen heeft met mij de laatste fase van het proces mee gemaakt en samen met mijn collega's mij de nodige steun gegeven om dit te realiseren, waarvoor ik zeer dankbaar ben.

Professor zur Hausen en de collega's op de afdeling klinische pathologie in Maastricht hebben mij open minded en warm ontvangen toen ik in januari van dit jaar in Maastricht begon. Elk begin is spannend en zij hebben het mij makkelijk gemaakt - ik dank jullie hiervoor.

Mijn 2 jongens, the boys, zijn voor mij steeds, ook hierbij, een grote motivatie door hun lieve toewijding en een beetje ook omdat ik hoop dat zij leren zowel van mijn successen als van mijn fouten.

Lo, jij bent sinds 2007 steeds, in goede en slechte tijden, mij toeverlaat, sparring partner en een onmisbare steun. Dank je.

Resteert nog u allen, dames en heren, te bedanken daarvoor dat jullie gekomen zijn. Het is nu tijd om met mij een glaasje te heffen op mijn activiteiten in Maastricht.

Ik heb gezegd.

\section{Literaratuur}

1. www.gutenberg.org/files/6400/6400-h/6400-h.htm

2. Rothenberg, Kelly (2008). "The Autopsy Through History". In Ayn Embarseddon, Allan D. Pass (eds.). Forensic Science. Salem Press. p. 100.

3. Costache M et al. Clinical or Postmortem? The Importance of the Autopsy; a Retrospective Study. Maedica J Clin Med 2014;9:261-265 
4. Burton EC et al. Autopsy Rate and Physician Attitudes Toward Autopsy http://emedicine.medscape.com/article/1705948

5. Grade MHC et al. Trends of accuracy of clinical diagnoses of the basic cause of death in a university hospital. J Clin Pathol. 2004;57:369-373

6. Perkins DG et al. Discrepancies between clinical and postmortem diagnoses in clinically ill patients: an observational study, Critical Care 2003;7:R129-R132

7. Kuijpers CCHL et al. The value of autopsies in the era of high-tech medicine: discrepant findings persist. J Clin Pathol 2014;67:512-519

8. Anders S et al. Autopsy in undergraduate medical education - what do students really learn? Int J Legal Med 2014;128:1031-1038

9. Bryce $\mathrm{CH}$. The Impact of Advances in Post-Mortem Imaging on Forensic Practice. J Forensic Sci Criminol 2013;1:e103. doi: 10.15744/23489804.1.e103

10. Ruder TD et al. Essentials of Forensic post-mortem MR imaging in adults. Br. J radiol 2014;87:2-130567

11. B. Buddeberg-Fischer et al, Swiss residents' sepeciality choices - impact of gender, personality traits, career motivation and life goals. BMC Health Services Res 2006;6:137-146

12. Gezondheidsraad. Werkprogramma 2013. Den Haag; publicatienr. A12/03. www.gezondheidsraad.nl/sites/default/files/Werkprogramma2013 A03 $\underline{0 . p d f}$

13. Forensische geneeskunde ontleed; naar een volwaardige plaats voor een bijzondere discipline 
www.rijksoverheid.nl/documenten/rapporten/2013/04/26/advies-

forensische-geneeskunde-ontleed

14. Sexton JS et al. Forensic pathology - the hidden specialty: a survey of forensic pathology training available to medical students and residents. J Forensic Sci 1979;24:275-281

15. K.B. Nolte KB. Research issues in forensic pathology: a survey of academic institutions employing forensic pathologists. Human Pathology $2004 ; 35: 532-535$

16. Gezondheidsraad. Werkprogramma 2014. Den Haag; publicatienr.. A13/02 http://www.gezondheidsraad.nl/sites/default/files/Werkprogramma_2014.pdf

17. www.eclm.info 